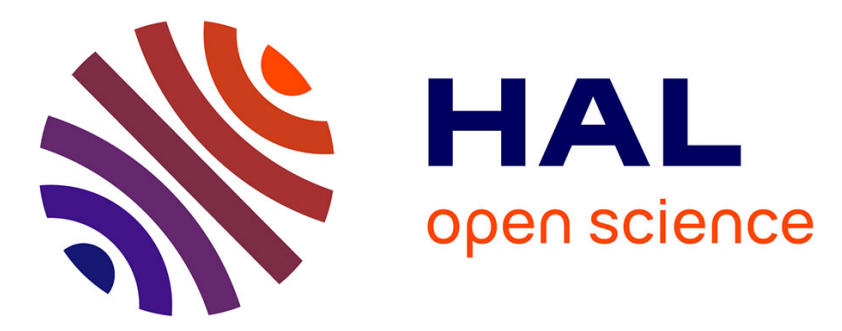

\title{
Study of Certain Magnetite and Mix Ferrite Magnetic Liquids in Static and Radiofrequency Fields
}

\author{
I. Malaescu, I. Hrianca, L. Gabor
}

\section{To cite this version:}

I. Malaescu, I. Hrianca, L. Gabor. Study of Certain Magnetite and Mix Ferrite Magnetic Liquids in Static and Radiofrequency Fields. Journal de Physique IV Proceedings, 1997, 07 (C1), pp.C1-563-C1564. 10.1051/jp4:19971233 . jpa-00254907

\section{HAL Id: jpa-00254907 https://hal.science/jpa-00254907}

Submitted on 1 Jan 1997

HAL is a multi-disciplinary open access archive for the deposit and dissemination of scientific research documents, whether they are published or not. The documents may come from teaching and research institutions in France or abroad, or from public or private research centers.
L'archive ouverte pluridisciplinaire HAL, est destinée au dépôt et à la diffusion de documents scientifiques de niveau recherche, publiés ou non, émanant des établissements d'enseignement et de recherche français ou étrangers, des laboratoires publics ou privés. 


\title{
Study of Certain Magnetite and Mix Ferrite Magnetic Liquids in Static and Radiofrequency Fields
}

\author{
I. Malaescu, I. Hrianca and L. Gabor* \\ West University of Timisoara, Department of Electricity and Magnetism, Bd. V. Parvan \# 4, 1900 \\ Timisoara, Romania \\ * "Politehnica" University Timisoara, P-ta Victoriei 2, 1900 Timisoara, Romania
}

\begin{abstract}
: the complex magnetic susceptibility components were determined for magnetic liquids based on magnetite and on mix ferrite of the type $\mathrm{Me}_{x} Z_{n_{1-x}} \mathrm{Fe}_{2} \mathrm{O}_{4}$, where Me can be either $\mathrm{Ni}$ or $\mathrm{Mn}$. A maxim of the imaginary component of the magnetic susceptibility was observed at freqencies of tens $\mathrm{MHz}$, assigned to relaxation processes of Néel type. The anisotropy constant of particles from the liquids studied was evaluated by using both static and dynamic measurements.
\end{abstract}

\section{Introduction}

The magnetization of magnetic liquids in a time varying field takes place either by rotating the particles in the basic liquid or by rotating the magnetic moment in the solid phase $[1,2,3]$. The relaxation processes which occur are of Brown type and Néel type. The Néel relaxation time, $\tau_{N}$, is correlated with the material properties of a particle through the anisotropy constant $K$ and its mean magnetic volume $V$ :

$$
\tau_{N}=\tau_{0} \exp \frac{K V}{k T}
$$

where $k$ is Boltzmann's constant, $T$ is the absolute temperature and $\tau_{0}$ is a constant having the magnitude $10^{-9} \mathrm{~s}$.

Due to the relaxation processes, the imaginary component $\chi^{\prime \prime}$ of the complex susceptibility show a maxim at a certain angular frequency $\omega_{\max }$. According to Debye, the relaxation time $r$ is correlated with this frequency through the relation:

$$
\omega_{\max } \tau=1
$$

In our papers $[3,4]$ we found maximum values of $\chi^{\prime \prime}$, coresponding to relaxation times of 10 ns for magnetic liquids having magnetite particles dispersed in kerosene, which we assigned to Néel relaxation. Fannin et. al. [5] have found two maximum values of the same component for a magnetic liquid having particles of $\alpha-\mathrm{Fe}_{2} \mathrm{O}_{3}$ dispersed in water. These maximum values corresponds to the relaxation times $\tau_{B}=318 \mu \mathrm{s}$ and $\tau_{N}=8.84 \mathrm{~ns}$ 。

In this paper we study how the real $\chi^{\prime}$ and imaginary components $\chi^{\prime \prime}$ of the complex susceptibility vary in the frequency range 1-100 $\mathrm{MHz}$ for magnetic liquids based on magnetite and on mix ferrite. From this study we determined the Néel relaxation time and the anisotropy constant.

\section{Experimental technique}

The components of complex susceptibility were determined using the method described in [3].The static magnetization curves were drawn using a ballistic galvanometer. For measurements were chosen four samples of magnetic liquids noted by A,B,C,D. Samples A and B are ferrofluids based on magnetite dispersed in kerosene which differ in concentration, mean particle diameter and method of obtaining. The coloidal particles of magnetite of the $B$ liquid were obtained by chemical co-precipitation and hydrofobized with oleic acid in the absence of dispersion medium [6]. Samples $\mathrm{C}$ and $\mathrm{D}$ are magnetic liquids based on mix ferrite dispersed in n-decan of type $\mathrm{Mn}_{0.4} Z n_{0.6} \mathrm{Fe}_{2} \mathrm{O}_{4}$ (sample $\mathrm{C}$ ) and $\mathrm{Ni}_{0.4} \mathrm{Zn}_{0.6} \mathrm{Fe}_{2} \mathrm{O}_{4}$ (sample D). The mix ferrite particles were obtained by co-precipitation from bivalent $\mathrm{Mn}^{2+}$ or $\mathrm{Ni}^{2+}$ and $\mathrm{Zn}^{2+}$ ion solutions and trivalent $\mathrm{Fe}$ at decreasing $\mathrm{pH}$. After that they were subject to a termic treatement and hydrofobized with oleic acid.

\section{Experimental results and discussions}

The measurements were performed at room temperature. For $C$ and D samples we observed that the magnetization $M$ dependence of the magnetic induction $B$ is of Langevin type, as for A and B samples [4]. In table 1 we show the 
saturation magnetization value $M_{\infty}$, the mean magnetic diameter $d$, the concentration of particles $n$ and the initial susceptibility $\chi_{i}$ for each sample. They were obtained using static measurements as it is shown in [4].

Table 1:Sample characteristics determined by static measurements

\begin{tabular}{|c|c|c|c|c|}
\hline Sample & $\begin{array}{c}M_{\infty} \\
(k A / m)\end{array}$ & $\begin{array}{c}n \\
10^{22} m^{-3}\end{array}$ & $\begin{array}{c}d \\
\mathrm{~nm}\end{array}$ & $\chi_{i}$ \\
\hline$A$ & 11.32 & 3.30 & 11.10 & 0.65 \\
\hline$B$ & 39.56 & 19.60 & 9.30 & 4.40 \\
\hline$C$ & 5.28 & 0.86 & 14.30 & 0.45 \\
\hline$D$ & 5.04 & 0.93 & 15.38 & 0.50 \\
\hline
\end{tabular}

Values for $M_{\infty}$ and $d$ for samples C and D are close to those recently found by Kuzubov and Ivanova [7] for samples of the same type $\left(\mathrm{Mn}_{0.5} \mathrm{Zn}_{0.5} \mathrm{Fe}_{2} \mathrm{O}_{4}\right.$ and $\left.\mathrm{Ni}_{0.5} Z_{n_{0.5}} \mathrm{Fe}_{2} \mathrm{O}_{4}\right)$. At the same time we mention that the values of $\mathrm{M}_{\infty}$ and $\chi_{i}$ for $C$ and $D$ samples are close to each other but that they are small compared to those of $A$ and $B$ samples.

The results of the measurements in RF field are shown in fig.1

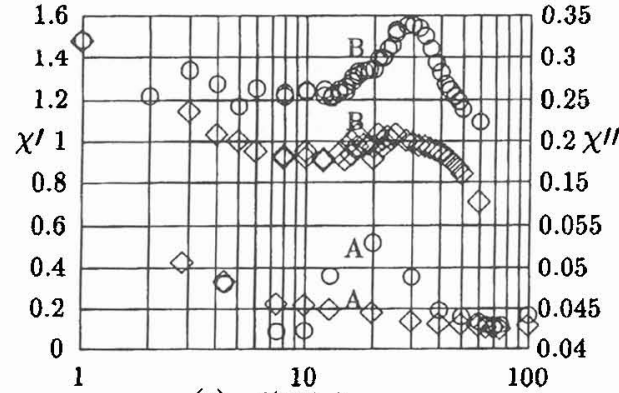

(a) $\mathbf{f}(\mathbf{M H z})$

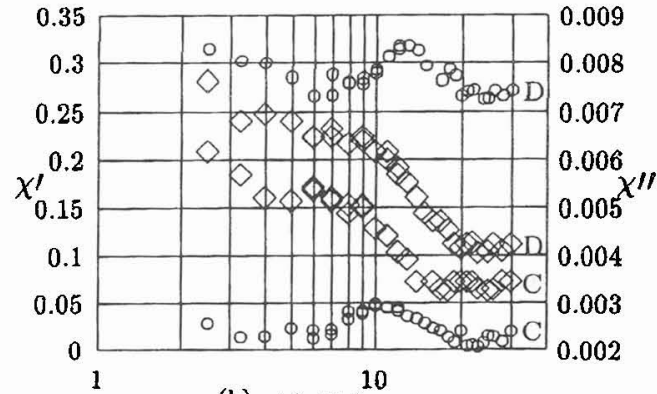

(b) $\mathrm{f}[\mathrm{MHz}]$

Figure 1: $\chi^{\prime}(0)$ and $\chi^{\prime \prime}(0)$ versus frequency $f$ for magnetic liquids $A$ and $B$ (a) respectively $C$ and $D$ (b)

The real components $\chi^{\prime}$ for $C$ and $D$ are smaller than those of $A$ and $B$ samples, but the shape of the curves is approximately the same. The imaginary component $\chi^{\prime \prime}$ show a maxim for all the four samples studied. We mention that the maxim for $\mathrm{C}$ and $\mathrm{D}$ samples lies in the decreasing region of $\chi^{\prime}$. The frequencies corresponding to the maxim for $\mathrm{C}$ sample (10 MHz) and D sample (13 MHz) are smaller than those corresponding to A sample (20 MHz) and B (30MHz). The corresponding relaxation times are (from eq. 2): $\tau_{N(A)}=8 n s, \tau_{N(B)}=5 n s, \tau_{N(C)}=16 n s, \tau_{N(D)}=12 n s$. Taking into account these values we consider that the corresponding relaxation processes are of Néel type. According to [4] the ratio of the mean diameters of the magnetite particles of A and B samples, is approximately the same when determined by using static and dynamic measurements. Consequently in eq.1 volume $V$ can be replaced by the volume determined using static measurements. Using $\tau_{N}$ for each sample and eq.1 we determined the anisotropy constant $K$ as follows: $K_{A}=12 \times 10^{4} \mathrm{erg} / \mathrm{cm}^{3}, K_{B}=14.4 \times 10^{4} \mathrm{erg} / \mathrm{cm}^{3}, K_{C}=1.9 \times 10^{4} \mathrm{erg} / \mathrm{cm}^{3}, K_{D}=1.3 \times 10^{4} \mathrm{erg} / \mathrm{cm}^{3}$.

It is well known that the anisotropy constant depends on the method of obtaining particles. For magnetite particles Raiker and Shliomis [8] show that the values of this constant are in the range $10^{4}-10^{5} \mathrm{erg} / \mathrm{cm}^{3}$. The values which we have found are within that range for both $\mathrm{Mn}$ and Ni mix ferrite particles. They are smaller than $7.2 \times 10^{4} \mathrm{erg} / \mathrm{cm}^{3}$ found by J.F.Dillon [9] for the sinterized $\mathrm{Ni}$ ferrite.

\section{References}

[1] P.C.Fannin, B.K.P. Scaife and S.W. Charles, J.Magn. Magn. Mater., 85 (1990) 54-56

[2] A.M.Konn, P.Laurent, P.Talbot and M.Le Floc'h, J. Magn. Magn. Mater., 140-144 (1995) 367-368

[3] I.Hrianca and I.Mălăescu, J.Magn. Magn. Mater., 150 (1995) 131-136

[4] I.Mălăescu and I.Hrianca, J. Magn. Magn. Mater 7266 (1996) (forthcoming)

[5] P.C.Fannin, B.K.P. Scaife and S.W.Charles, J.Magn. Magn. Mater 122 (1993), 159-163

[6] I.Hrianca, L.Gabor, I.Mălăescu, A.Ercuta and F.Claici, forthcoming article in Romanian Reports in Physics, (1995)

[7] A.O.Kuzubov and O.I. Ivanova, J.Phys. III France 4 (1994) 1-6

[8] Y.L.Raikher and M.I.Shliomis, Adv.Chem.Phys., 87 (1994) 8.

[9] J.F.Dillon and H.E.Earl, J.Appl.Phys. 30 (1958) 202 